\title{
Retaking a course in Economics: Innovative teaching strategies to improve academic performance in groups of low-performing students
}

\author{
Gemma Abío , Manuela Alcañiz ${ }^{\mathrm{b}}$, Marta Gómez-Puig ${ }^{\mathrm{a}}$, Glòria Rubert ${ }^{\mathrm{a}}$, Mònica \\ Serrano $^{\mathrm{a}}$, Alexandrina Stoyanova ${ }^{\mathrm{a}}$, Montserrat Vilalta-Bufí ${ }^{\mathrm{a}}$ \\ ${ }^{a}$ Department of Economics, Faculty of Economics and Business, University of Barcelona (Spain). \\ ${ }^{\mathrm{b}}$ Department of Econometrics, Statistics and Applied Economics, Faculty of Economics and Business, \\ University of Barcelona (Spain).
}

August 2017

\begin{abstract}
Students who have to retake courses at university are often not only low achieving, but also unmotivated and lacking in self-confidence. In this study, we present the first report of a teaching strategy based on the implementation of the flipped classroom model, team-based learning, and frequent testing strategies in groups of students retaking a subject. A sample of seven groups of an average of 68 students followed the new teaching approach. The groups are distributed across four subjects and three semesters. By comparing the average performance across groups that apply different teaching strategies - traditional versus innovative - we find a significant increase in the academic performance of the students following the new approach.
\end{abstract}

Keywords: Teaching innovation; flipped classroom; team-based learning; frequent testing; large groups; retake subjects; economics.

JEL Classification Codes: A20, A22

\footnotetext{
* Correspondence address: Montserrat Vilalta-Bufi; Department of Economics, Faculty of Economics and Business; Av. Diagonal 696; 08034 Barcelona (Spain). E-mail: montsevilalta@ub.edu; Phone: +34 934024572, Fax; +34 934039082. This paper is based upon work supported by the University of Barcelona and the Institute of Sciences of the Education under grants' numbers 2014PID_UB/031 and REDICE16-1462.
} 


\section{Introduction}

Since the adoption of innovative techniques to promote the engagement of students in active learning, university teaching has frequently diverged from the traditional lecture schema. The introduction of active learning techniques in the classroom strives to change the way of studying by encouraging students' active participation in the learning process. This is especially necessary for those students that experience some academic difficulty and need to retake a course at any stage of their degree programme. It has been suggested that some of these students have a poor knowledge background which hampers their learning process, while others lack the skills and learning habits required to perform successfully in the educational setting (Kruger and Dunning, 1999; Pennebaker et al., 2013). However, despite the importance of designing active learning techniques that can help low-achieving students improve their academic performance, the issue does not appear to have been studied so far in this specific group of students. The present paper aims to fill this gap in the literature.

In this context, Flipped Classroom and Team-Based Learning stand out as leading activelearning strategies. Flipped classroom is a pedagogical strategy that focuses on the importance of the use of class time for the construction of knowledge rather than the transmission of information. It reverses the traditional educational arrangement: students prepare content and concepts before the class time, and the classroom is transformed into a dynamic space where the instructor guides the students through an interactive learning environment. The beginning of flipped classroom can be traced to the 1990s (King, 1993; Mazur, 1997; Crouch and Mazur, 2001) and it became popular during the 2000s (Bergmann and Sams, 2012). Many studies support its success (McLaughlin, 2013; Missildine et al., 2013; Wilson, 2013), and highlight the improvements in students' achievements, participation and attitudes toward learning and teaching, and a greater satisfaction of teachers involved in the model (Lage et al., 2000; Berrett, 2012; Strayer, 2012; Chung, 2014; and Prieto et al., 2014). 
In the team-based learning approach, traditional lectures play a minor role and they are substituted by activities devoted to interactions between small groups of students. These activities not only reinforce students' knowledge and learning processes (Nordberg, 2008; Shah, 2013; Opdecam et al., 2014), but also help them to develop their interpersonal communication skills (Michaelsen et al., 2004). A cooperative learning strategy, therefore, enhances the interconnection between students who, through their involvement in a common project, improve their academic performance (Yamarik, 2007), increase their self-esteem, and foster a spirit of teamwork (Millis and Cottell, 1998).

Besides these two active learning strategies, another instrument that can help students to develop their learning habits is Frequent Testing. For Roediger et al. (2011), the benefits of testing go beyond mere assessment. Quizzes allow students to identify the gaps in their knowledge, provide professors with feedback on their students' progress and, most importantly, improve learning. Moreover, within testing activities, teamwork has shown to increase students' engagement and to enhance the productive learning behaviours of both low- and highachievers (Hong and Pham, 2013).

As far as we know, the present study is the first to analyse the benefits of a more interactive classroom format in groups of students retaking a course. We present the results of our experience with the use of these three strategies - flipped classroom, team-based learning, and frequent testing - with students retaking a subject in special groups called Groups of Intensive Study (GIS) at the University of Barcelona, Spain. The incorporation of these learning activities to motivate and organize their work at both individual and team level has resulted in a significant improvement in the students' academic performance.

The study was carried out over the academic years 2013/14 and 2014/15, in four subjects: Microeconomics from the Business Administration Bachelor Degree (BA), and Introduction to Economics, Microeconomics I, and Microeconomics II of the Economics Bachelor Degree 
(ECO). The results show a significant increase in the academic performance of these students and suggest that this educational strategy may also be helpful in the teaching of many other subjects.

The paper is organized as follows. In Section 2, we describe the context of the experience. Section 3 presents the teaching strategies proposed for improving the academic achievements of GIS students. Results are reported in section 4. Finally, section 5 concludes.

\section{The Groups of Intensive Study (GIS)}

In the 2011/12 academic year, the University of Barcelona introduced the GIS for students retaking a course. Like the regular groups, the GIS bear 6 ECTS credits. However, while a regular group entails 60 hours of face-to-face activities, a GIS group devotes only 30 hours to face-to-face activities. This structure represents an increase in both the work supervised by the lecturer, who has to prepare additional online materials for guided self-study, and the time students are required to devote to autonomous learning. At the same time, it frees up students' class schedule so that it is easier to combine the retake of the failed course with the classes of the new subjects.

During the 2011/12 and 2012/13 academic years the face-to-face activities in GIS mainly focused on problems solving. GIS students were expected to self-prepare the core theoretical aspects using the online material. However, this blended learning format turned out to be quite inefficient. The results of GIS groups were very disappointing: the attendance of face-to-face activities, the percentage of students who showed up for the exams and the proportion of those who passed the course were lower than in the regular groups. A possible explanation might be the characteristics of the students who enrol in the GIS. Repeat students are not a representative sample of the general population of students and are more likely to have learning difficulties and poorer outcomes. While there are no significant differences between GIS and regular 
groups in terms of gender (around $38 \%$ of students are female), the GIS students tend to be a year or two older than those in regular groups, as they repeated the subject at least once (20-21 years old). Our experience with these students showed that they might have a lower capacity for analysis and synthesis, a lesser ability to organize their work and to manage their time, and less motivation to study. The poor performance of the GIS in the first two years of the implementation led us to implement a new teaching strategy to address better these students' needs and to help them successfully move ahead in their studies.

\section{Teaching strategy}

To improve the learning performance of students in the GIS, we propose a strategy based on the joint implementation of the flipped classroom, team-based learning and frequent testing strategies. During the second semester of 2013/14 and throughout the 2014/15 academic year, we carried out a trial experiment in four subjects - Microeconomics (BA), Introduction to Economics (ECO), Microeconomics I (ECO), and Microeconomics II (ECO) - to test the results of this teaching approach and to improve the strategy design for future implementations.

\subsection{Description of the teaching strategy}

In each subject, students can choose between two evaluation schemes: continuous assessment or single assessment. The student's evaluation under continuous assessment consists of a weighted average of several items, which often include several activities during the course and a final exam. In contrast, the single evaluation includes only the grade of a final exam. In this section, we describe the learning activities used in the continuous assessment of the GIS. These activities develop a constructive alignment between the intended learning outcomes, the teaching/learning activities and the assessment tasks (Biggs and Tang 2011).

Students are grouped into stable teams of three or four members. The aim of creating stable groups is to reinforce commitment to the group work. Class attendance is mandatory. The 
programming of each session and the material for students is announced in advanced in the digital platform of the subject. Each session can be either theoretical or practical classes.

Theoretical sessions start with a test: students have to answer an individual multiple-choice quiz of 10 questions based on the material that they are given in advance. Immediately afterwards, students solve the same 10 multiple-choice questions in their teams. This exercise obliges students to discuss the questions and to reach a consensus with their colleagues on the right answer. Both quizzes are evaluated and last 15-25 minutes each. Finally, the test is resolved in the whole class, solving all the doubts and questions that might arise. The remaining time of the session (around 30-40 minutes) is devoted to explain the topic's more complex theoretical concepts. Practical sessions consist of the resolution, in teams, of applied exercises in the classroom. These are numerical and graphical problems related to the topic. In order to encourage participation in the teamwork and to increase further students' motivation, the first team that solves an exercise can explain it on the board to the rest of the class and get extra points (see Table 1 below). Although this was not the primary objective of our strategy, the presentation of the solutions on the board can also be considered as an important part of developing and improving students' presentation skills.

During the last week of the course, students are asked to fill in self-assessment and coassessment questionnaires in which they evaluate their own work and that of their teammates. Finally, students have to solve a final exam.

\subsection{Grading system}

The assessment and learning activities in GIS are designed to help students to successfully follow the subject, meet the learning objectives, and demonstrate their progress. Table 1 provides a breakdown of all components included in the grading system not only for the GIS, but for the regular groups as well. 
[Insert Table 1 about here]

It is worth stressing that both the content of the subject and the final exam is the same for all students - that is, those in the GIS and those in the regular groups. All students, both regular and GIS, can choose between continuous assessment and single assessment. Moreover, in the case of students that choose continuous assessment, the overall weight of continuous assessment activities (40\%) and that of the final exam (60\%) in the final course grade is the same in both group types. Therefore, the only grading difference between students enrolled in GIS and in regular groups is the type of the continuous assessment activities. They are presented in Table 1. The activities followed by students enrolled in GIS aim to stimulate autonomous learning before class and to foster active participation during the two-hour weekly sessions, whereas the two continuous assessment tests in the regular groups are performed after the explanation of the corresponding topics or units. Moreover, the continuous assessment in the new approach includes frequent testing, while in the regular groups only a few activities are evaluated during the course.

\section{Results and discussion}

A total of 610 students were enrolled in one of the GIS under study, distributed in seven groups of an average of 87 students. These groups correspond to one group of the Microeconomics (BA) and one group of Microeconomics I (ECO) in the academic year 2013/2014, two groups of Microeconomics (BA) and one group of Microeconomics I (ECO) in 2014/2015, and one group of Introduction to Economics (ECO) and Microeconomics II (ECO) in 2014/2015.

All the students enrolled in a GIS had attended regular classes of the subject over the past 1 to 3 years, and had failed. The size of the GIS varied between 28 and 114 enrolled students. Of the 610 students, 476 (78\%) followed the new teaching approach; this percentage varied from $63.6 \%$ to $92.2 \%$ depending on the group. The remaining $22 \%$ of all enrolled students chose the single assessment option. Although they were encouraged to attend GIS classes and to do the weekly multiple-choice quizzes, most of them never did so. 


\subsection{Overall student performance in the GIS with the new teaching approach}

The implementation of the new teaching approach in the GIS led to an increase in both the percentage of students who show up for the final exam and the percentage of those who passed by around $29 \%$ and $50 \%$, respectively.

Figure 1 compares the show up rates for students in GIS and in regular groups before and after the introduction of new teaching strategy in the GIS. ${ }^{1}$ The percentage of students who turn up to the final exam slightly higher among those enrolled in GIS following the new teaching model as compared to those enrolled in regular groups. This represents a significant improvement, as before the implementation of the new teaching strategy in GIS, the show up rate among GIS students was 22 points lower than among regular students.

\section{[Insert Figure 1 about here]}

This rise in the show up rate for the final exam may have been due to the increased class attendance and the participation in the frequent continuous assessments. Indeed, before the implementation of the new teaching strategy, attendance in the GIS was very low - below $25 \%$, even though the assessment scheme was the same as in traditional groups and the students could choose between continuous and single assessment in both cases.

The higher show up rates for the final exam went hand in hand with higher pass rates. The latter effect is reported in Figure 2, which displays the percentage of students who passed the subject, distinguishing between regular groups and GIS. The first two columns refer to the 2011/12 and 2012/13 academic years, before the introduction of the new strategy, and the last two columns correspond to 2013/14 and 2014/15, when the new strategy was in place. The results reveal that

\footnotetext{
${ }^{1}$ The regular groups have similar average size to the GIS. We use the regular groups of the same subjects under study. They are always a larger sample than the GIS. They represent in total around 6,400 students for the period before and over 4,800 students for the period after the implementation of the new teaching approach.
} 
the introduction of the new teaching approach raised pass rates among GIS students by nearly $50 \%$ (from 46.9 to $68.1 \%$ ), while in the regular groups the pass rate actually fell slightly.

\section{[Insert Figure 2 about here]}

Since teaching in GIS and in regular groups only differs in the type and number of continuous assessment activities, the above findings suggest that it is the new teaching strategy in the GIS (which encourages autonomous learning and increases students' collaborative learning skills) that might be behind the improvement in academic performance.

In order to check the robustness of the results, we control for potential selection problems (among them, subject and professor). During the academic year 2013/14, the subject Microeconomics for BA, was taught in regular groups, and two GIS, but only one of them applied the new teaching approach; on enrolment, students were randomly assigned to one of the GIS groups. The results show that the new teaching approach clearly increased the pass rate of repeater students, which was around $72 \%$ in the regular groups, $42 \%$ in the GIS with standard teaching approach and $63 \%$ in the GIS that applied the new teaching strategy.

Figure 3 shows the results of two groups (GIS and a regular group) on the same subject (Microeconomics for BA) taught by the same professor during three academic years: 2013/14 (without implementing the new teaching approach in the GIS) and in 2013/14 and 2014/15 (applying the new teaching strategy in the GIS). It can be observed that the percentage of students who passed the subject was clearly lower in the GIS group than in the regular group before implementing the new teaching approach, but was quite similar in the two groups in the academic years following its introduction.

\section{[Insert Figure 3 about here]}

Finally, we applied a last robustness test in order to analyse whether the improvement was due to the new teaching methods or to a learning curve inherent to any new program, that is, whether 
there may have been a possible 'learning effect' in professors teaching the GIS groups, which might have biased the results. We compared the performance of students enrolled on regular and GIS groups in four subjects - Introduction to Economics (BA), Microeconomics (BA), Microeconomics I, and Microeconomics II (ECO) — taught by professors at the Department of Economics who applied only standard teaching methods, during the academic years before and after the introduction of the new teaching approach in the other GIS groups. In the subjects where the new strategy in the GIS groups was not implemented in academic year 2013/14, the performance did not improve over time, meaning the rise in pass rates after applying the new teaching strategy in GIS group (Figure 2) cannot be attributed to a 'learning effect'.

All in all, even after controlling for potential selection problems or a possible 'learning effect', the results of our analysis show that a combined learning strategy based on flipped classroom, team-based learning and frequent testing with students retaking a course improve academic performance.

\subsection{Results from the self-administered survey}

In order to assess the students' opinions about the new teaching strategy, we asked them to take an online survey as part of the coursework. The completion of the survey questionnaire was not mandatory, but if totally completed it accounted for $10 \%$ of the final grade (see Table 1 ). The survey contained self-assessment questions as well as joint assessment questions related to the involvement of other members of the student's team. A limited space for a short evaluation of the new learning activities was also provided. Three out of four students of those who followed the new teaching approach completed the questionnaire.

Firstly, the students were asked whether they had regularly attended classes during the previous year, when they had failed the subject. The answers show that almost $70 \%$ attended more than half of the classes or had attended classes quite regularly. Secondly, students were asked to 
think about why they had failed the subject the previous year. Multiple responses were allowed. More than half of students reported not studying regularly and $35 \%$ reported that they did not prepare sufficiently for the exam. Around one fifth of students considered that they could have done better had they chosen continuous assessment. The new approach aimed at helping students to study regularly, encouraging them to review the material before each class and to prepare better for the final exam. The increase in the academic performance, together with the overall satisfaction revealed in the self-administered survey, suggest that we are on the right way to accomplish the proposed goals.

The students were also asked which of the teaching approach they preferred, i.e., the one applied in other GIS or regular groups or the new one implemented in the study. Around $68 \%$ stated they would choose the new approach over the standard one, and $12 \%$ said that they would like to follow a combination of the two strategies or a modified version of the new one. The remaining 20\% declared they would prefer the standard teaching approach because of the mandatory class attendance and the autonomous learning before the weekly multiple-choice tests. However, all students (regardless of their preferences) declared that the most positive feature of the teaching strategy was the teamwork and the skills related to it developed during sessions and during the time they dedicated to prepare for the exams.

[Insert Table 2 about here]

The new teaching strategy helped students fulfil the learning objectives of the subject and pass the exam. They were also more motivated to attend classes, study regularly, and review the course material. The item that got the lowest evaluation in the self-assessment questionnaire was the active participation in the class, with an average evaluation of 3.4 out of 6 . 


\section{Conclusions}

This paper proposes a combination of flipped classroom, team-based learning and frequent testing strategies to enhance the academic performance of students that retake a course. To the best of our knowledge, those type of students, that form a group of major concern, have not received much attention by researchers in teaching innovation.

The results suggest that students benefit from guided autonomous study, the continuous feedback they receive, and the teamwork. The gains are mainly reflected in: (1) the increase in the percentage of students who sat the final exam and (2) the higher pass rate. Results hold when controlling for potential selection problems or for possible 'learning effects'.

The students' responses to the self-administered survey suggest that they attended classes on a more regular basis and worked harder than in previous courses. We conjecture that the subjects' higher engagement increased their motivation to learn (Bryson and Hand, 2007). Moreover, the new teaching approach is widely accepted among students. Although in general students seemed not to welcome the autonomous work, they valued a lot the teamwork and the collaborative learning environment.

The proposed teaching approach requires a high involvement by the professor in developing activities and grading continuous assessment activities. Working together with other colleagues and the use of new technologies for self-assessment might be the ways to go in order to reduce the considerable time cost. In our experience, the positive results outweigh the costs of applying the proposed teaching approach.

Although the study was carried out with groups of students re-taking Economic Theory courses, the success suggests that the new teaching approach may well be applied in other subject areas and in groups of students taking a course for the first time. 


\section{References}

Bergmann, J., and Sams, A. 2012. Flip your classroom: Reach every student in every class every day. Washington, D.C.: International Society for Technology in Education.

Berrett, D. 2012. How 'flipping' the classroom can improve the traditional lecture. The Chronicle of Higher Education. http://chronicle.com/article/How-Flipping-theClassroom/130857/

Biggs, J., and Tang, C. 2011. Teaching for quality learning at university. $4^{\text {th }}$ Ed. Ed. Maidenhead, UK: McGraw Hill.

Bryson, C., and Hand, L. 2007. The role of engagement in inspiring teaching and learning, Innovations in Education and Teaching International 44, 349-362.

Chung, K. 2014. Professors 'flip' classrooms, enhance learning. Daily Tar Heel. Retrieved. http:/www.dailytarheel.com/article/2014/01/flipped-classrooms-0108

Crouch, C., and Mazur, E. 2001. Peer Instruction: Ten Years of Experience and Results, American Journal of Physics 69, 970-977.

Hong, T., and Pham, T. 2013. Using group projects as a strategy to increase cooperation among low- and high-achieving students. Higher Education Research and Development 32, 993-1006.

King, A. 1993. From sage on the stage to guide on the side. College teaching 41, 30-35.

Kruger, J., and Dunning, D. 1999. Unskilled and unaware of it: How difficulties in recognizing one's own incompetence lead to inflated self-assessments. Journal of Personality \& Social Psycology 77, 1121-1134.

Lage, M.J., Platt, G.J., and Treglia, M. 2000. Inverting the classroom: A gateway to creating an inclusive learning environment. The Journal of Economic Education 31, 30-43.

Mazur, E. 1997. Peer Instruction: A User's Manual Series in Educational Innovation. Prentice Hall, Upper Saddle River, NJ.

McLaughlin, J.C. 2013. Pharmacy student engagement, performance, and perception in a flipped satellite classroom. American Journal of Pharmaceutical Education 77, 1-8.

Michaelsen, L.K., Knight, A.B., and Fink, L.D. 2004. Team-Based Learning: A Transformative Use of Small Groups in College Teaching. Sterling, Va. Stylus.

Millis, B.J., and Cottell, P.G. 1998. Cooperative Learning for Higher Education Faculty. Phoenix, Ariz. Oryx Press. 
Missildine, K., Fountain, R., Summers, L., and Gosselin, K. 2013. Flipping the classroom to improve student performance and satisfaction. Journal of Nursing Education 52, 597- 599.

Nordberg, D. 2008. Group projects: More learning? Less fair? A conundrum in assessing postgraduate business education. Assessment \& Evaluation in Higher Education 33, 481-492.

Opdecam, E., Everaert, P., and Van Keer, H. 2014. Preferences for Team Learning and LectureBased Learning Among First-Year Undergraduate Accounting Students. Research in Higher Education 55, 400-432.

Pennebaker, J.W., Gosling, S.D., Ferrell, J.D. 2013. Daily Online Testing in Large Classes: Boosting College Performance while Reducing Achievement Gaps. PloS ONE 8, 11, e79774.

Prieto, A.;, Díaz, D., Montserrat, J., Reyes, E. 2014. Experiencias de aplicación de estrategias de gamificación a entornos de aprendizaje universitario. ReVisión, 7.

Roediger, H.L. III, Putnam, A.L., Smith, M.A. 2011. Ten benefits of testing and their applications to educational practice. Edited by: Mestre, J.P., Ross, B.H. Psychology of Learning and Motivation: Cognition in Education Book Series: Psychology of Learning and Motivation, Volume: 55 Pages: 1-36.

Shah, S.Z.A. 2013. The use of group activities in developing personal transferable skills. Innovations in Education and Teaching International 50, 297-307.

Strayer, J. 2012. How learning in an inverted classroom influences cooperation, innovation and task orientation. Learning Environments 15, 171-193.

Wilson, S.G. 2013. The flipped classroom: A method to address the challenges of an undergraduate statistics course. Teaching of Psychology 40, 193-199.

Yamarik, S. 2007. Does cooperative learning improve student learning outcomes? Journal of Economic Education 38, 259-277. 


\section{Tables}

\section{Table 1. Summary of assessment policy according to type of group of enrolment}

\begin{tabular}{|c|c|c|c|}
\hline \multicolumn{2}{|c|}{ Assessment in GIS } & \multicolumn{2}{|c|}{ Assessment in regular groups } \\
\hline Grading Activities & $\begin{array}{l}\text { \% of the Final } \\
\text { Grade* }\end{array}$ & Grading Activities & $\begin{array}{l}\% \text { of the Final } \\
\text { Grade* }\end{array}$ \\
\hline Final exam & $60 \%$ & Final exam & $60 \%$ \\
\hline Average of all individual tests & $15 \%$ & Test 1 of continuous assessment & $15 \%$ \\
\hline Average of all team tests & $15 \%$ & Test 2 of continuous assessment & $15 \%$ \\
\hline $\begin{array}{l}\text { Self- and co-assessment } \\
\text { questionnaire }\end{array}$ & $10 \%$ & $\begin{array}{l}\text { Homework assignments and class } \\
\text { participation }\end{array}$ & $10 \%$ \\
\hline $\begin{array}{l}\text { Team problem solving and } \\
\text { presentation* }\end{array}$ & $0-10 \%$ & & \\
\hline
\end{tabular}

* The $10 \%$ of the final grade corresponding to this category is an extra-credit option. It is obtained only by students who actively participate in team problem solving and who present the solutions on the board to the rest of the teams.

\section{Table 2. Results from the self-assessment questionnaire}

\begin{tabular}{|c|c|c|}
\hline Questions & Mean value* & Std. dev. \\
\hline I actively participated in the team work & 5.2 & 0.96 \\
\hline I had a good relationship with the other members of my team & 5.7 & 0.75 \\
\hline I spent enough time studying the subject & 4.1 & 1.03 \\
\hline $\begin{array}{l}\text { I worked autonomously in order to achieve the objectives of the course (reviewing the } \\
\text { material, reading the manual, solving problems, etc.) }\end{array}$ & 4.2 & 1.17 \\
\hline I actively participated in classroom activities and discussions & 3.4 & 1.50 \\
\hline I used to pay attention in class & 4.8 & 1.01 \\
\hline I had the right attitude during classes (paid attention, do not disturb classmates, etc.) & 5.3 & 0.87 \\
\hline I am satisfied with my progress in the subject & 4.2 & 1.23 \\
\hline $\begin{array}{l}\text { I found the new strategy very helpful to learn the subject and it helped me to successfully } \\
\text { complete the course }\end{array}$ & 4.3 & 1.49 \\
\hline I prefer the new strategy to the standard one used in other GIS courses & 4.3 & 1.81 \\
\hline $\begin{array}{l}\text { I think that the new strategy has made me study regularly and work harder during the term } \\
\text { compared to other GIS courses }\end{array}$ & 4.4 & 1.71 \\
\hline $\begin{array}{l}\text { The new strategy has made me attend classes on a regular bases compared to other GIS } \\
\text { courses }\end{array}$ & 5.0 & 1.48 \\
\hline
\end{tabular}

Note: * A six-point scale ranging from 'totally disagree' (1) to 'totally agree' (6) was used to collect the data from the self-assessment survey. 
Figure 1. Percentages* of students who showed up for the final exam by type of enrolment.

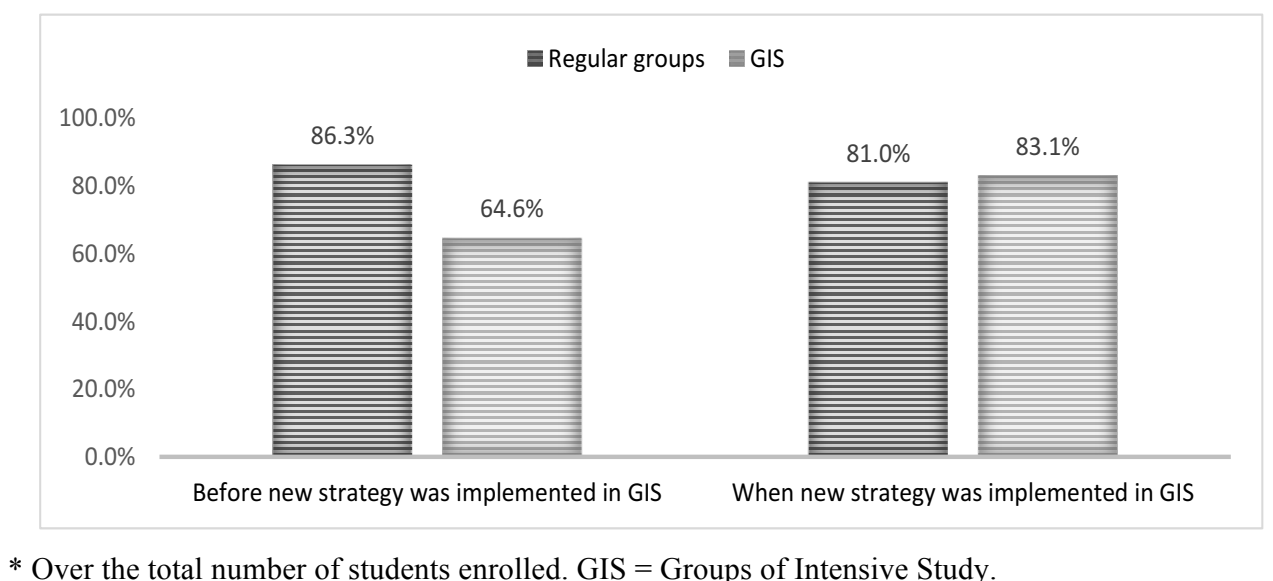

* Over the total number of students enrolled. GIS = Groups of Intensive Study.

Figure 2. Percentages* of students who passed the subject, by type of enrolment.

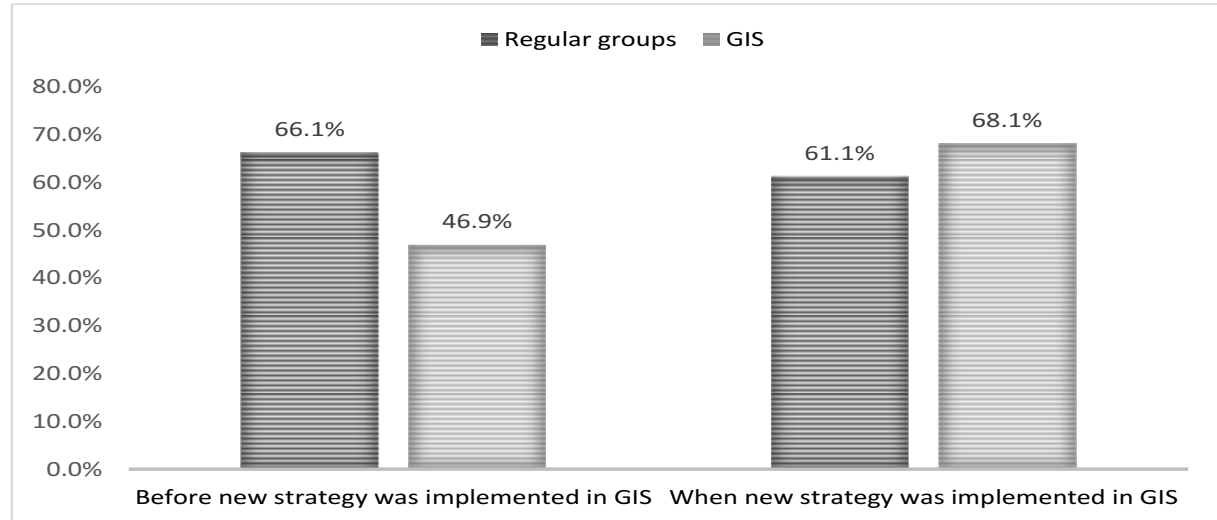

* Over the total number of students who took the final exam. GIS = Groups of Intensive Study.

Figure 3. Percentages* of students who passed Microeconomics (BA) with the same professor, according to type of enrolment.

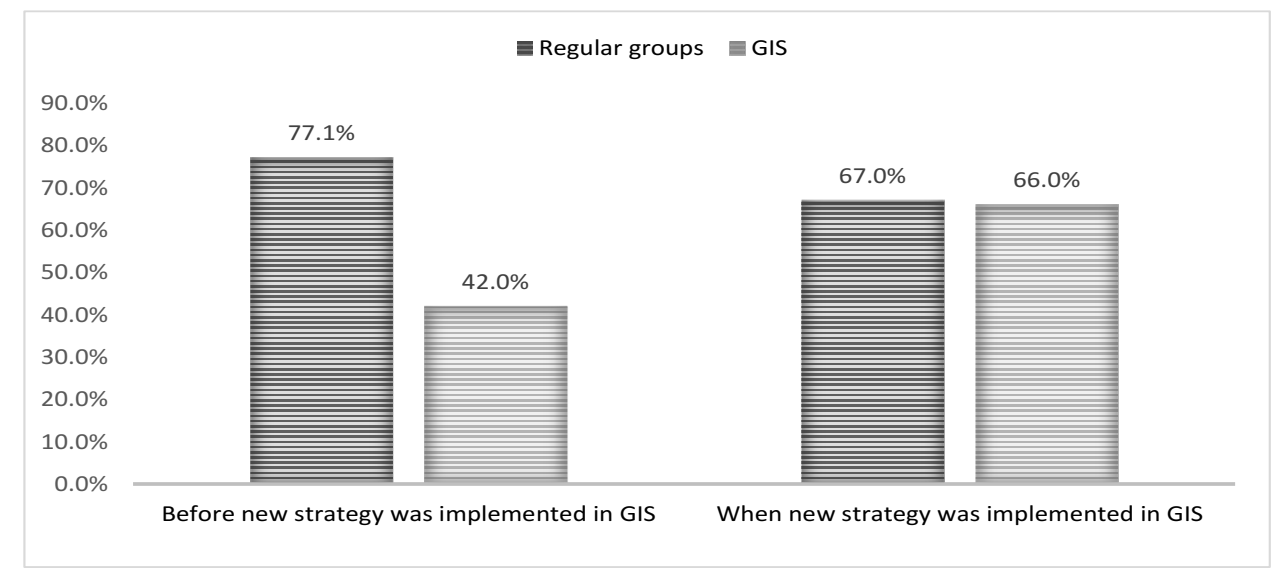

* Over the total number of students who took the final exam. GIS = Groups of Intensive Study. 